\title{
Simulation and Analysis on Machining Channels in the Electrochemical Pattern Transfer Method
}

\author{
Zhe Wang, Shuangqing Qian ${ }^{*}$, Hongbei Cao, Hua Zhang, Kai Bao \\ School of Mechanical Engineering, Nantong university, Nantong 226019, P. R. China \\ *E-mail: sqqian@ntu.edu.cn
}

doi: $10.20964 / 2016.07 .25$

Received: 30 March 2016 / Accepted: 11 April 2016 / Published: 4 June 2016

\begin{abstract}
Proton exchange membrane fuel cell (PEMFC) is considered as a preferred clean and efficient energy, and its flow channel structure design and forming technology directly affect the efficiency of power generation. In this work, the shape evolution of flow channels in electrochemical pattern transfer machining (ECPTM) was studied carefully and the influences of machining time, inter-electrode gap, insulation thickness, and opening and spacing ratio of channel on the electric field distribution and processing localization were investigated numerically. The results demonstrated that the insulation thickness had almost no effect on the electric field distribution, whereas the inter-electrode gap showed an important influence on both electric field distribution and processing localization. When the opening and spacing ratio of channel was more than 1:3, there were no interferences between channels and a higher spatial resolution could be obtained in both simulation and experiment.
\end{abstract}

Keywords: Flow channel; Electrochemical pattern transfer; Finite element simulation; Localization; Spatial resolution;

\section{FULL TEXT}

(C) 2016 The Authors. Published by ESG (www.electrochemsci.org). This article is an open access article distributed under the terms and conditions of the Creative Commons Attribution license (http://creativecommons.org/licenses/by/4.0/). 